\title{
Oxygen Reduction on Gas-Diffusion Electrodes for Phosphoric Acid Fuel Cells by a Potential Decay Method
}

\author{
Li, Qingfeng; Gang, Xiao; Hjuler, Hans Aage; Berg, Rolf W.; Bjerrum, Niels
}

Published in:

Journal of The Electrochemical Society

Link to article, DOI:

$10.1149 / 1.2049970$

Publication date:

1995

Document Version

Publisher's PDF, also known as Version of record

Link back to DTU Orbit

Citation (APA):

Li, Q., Gang, X., Hjuler, H. A., Berg, R. W., \& Bjerrum, N. (1995). Oxygen Reduction on Gas-Diffusion Electrodes for Phosphoric Acid Fuel Cells by a Potential Decay Method. Journal of The Electrochemical Society, 142(10), 3250-3256. https://doi.org/10.1149/1.2049970

\section{General rights}

Copyright and moral rights for the publications made accessible in the public portal are retained by the authors and/or other copyright owners and it is a condition of accessing publications that users recognise and abide by the legal requirements associated with these rights.

- Users may download and print one copy of any publication from the public portal for the purpose of private study or research.

- You may not further distribute the material or use it for any profit-making activity or commercial gain

- You may freely distribute the URL identifying the publication in the public portal 


\title{
Oxygen Reduction on Gas-Diffusion Electrodes for Phosphoric Acid Fuel Cells by a Potential Decay Method
}

\author{
Li Qingfeng," Xiao Gang," H. A. Hjuler, ${ }^{*}$ R. W. Berg, and N. J. Bjerrum* \\ Materials Science Group, Department of Chemistry, Technical University of Denmark, 2800 Lyngby, Denmark
}

\begin{abstract}
The reduction of gaseous oxygen on carbon-supported platinum electrodes has been studied at $150^{\circ} \mathrm{C}$ with polarization and potential decay measurements. The electrolyte was either 100 weight percent phosphoric acid or that acid with a fluorinated additive, potassium perfluorohexanesulfonate $\left(\mathrm{C}_{6} \mathrm{~F}_{13} \mathrm{SO}_{3} \mathrm{~K}\right)$. The pseudo-Tafel curves of the overpotential vs. $\log \left(i i_{L} /\left(i_{1}-i\right)\right)$ show a two-slope behavior, probably due to different adsorption mechanisms. The potential relaxations as functions of $\log (t+\tau)$ and $\log (-d \eta / d t)$ have been plotted. The variations of these slopes and the dependence of the double-layer capacitance on the overpotential depended on the electrode manufacture and the kind of electrolyte (whether containing the fluorinated additive or not).
\end{abstract}

\section{Introduction}

Much experimental work has been done to determine the Tafel slope and exchange current for the electrochemical reduction of oxygen in acidic electrolytes. Two Tafel regions were found by Sepa and co-workers ${ }^{1}$ on a rotating smooth platinum electrode in sulfuric acid; in the low polarization region the Tafel slope was $2.303 R T / F$, and in the high polarization region the Tafel slope was $2(2.303 R T) / F$. The transition of the slopes was interpreted in terms of the first charge-transfer step being rate determining in both potential regions but under Temkin adsorption on an oxygen-covered surface in the low polarization region, and Langmuirian adsorption on an oxygen-uncovered surface in the high polarization region. In phosphoric acid electrolyte, a similar behavior was observed on smooth platinum electrodes. ${ }^{2-5}$

However, gas-diffusion electrodes with high surface-area platinum (supported on carbon) are presently used in phosphoric acid fuel cells (PAFC). There is always the question of the applicability of kinetic data obtained on low-surface-area electrodes (wires, beads, foils, etc.) to high-surface-area dispersed electrocatalysts. It seems reasonable, therefore, that the kinetic parameters should be obtained on the highly dispersed electrocatalysts directly by using gas-diffusion electrodes. Compared with smooth platinum electrodes, complications are encountered with the carbonsupported platinum gas-diffusion electrodes, such as problems with supporting the electrocatalyst, preparative techniques, preconditioning, experimental conditions, etc. The electrochemical measurement involves the polarization losses caused mainly by the finite conductivity of the electrolyte, electrode matrix, and diffusion of reactants and products. Controversies therefore exist concerning measurements of kinetics of oxygen reduction on gas-diffusion electrodes. Tafel slopes ranging from 65 to $180 \mathrm{mV} /$ decade have been reported. . $^{6-12}$.

Most investigators ${ }^{6-9}$ believed that the working mechanism of gas-diffusion electrodes, among other things, was a main factor affecting the magnitude of the Tafel siopes. When controlled by the kinetic process, the electrode exhibits a Tafel slope smaller than $120 \mathrm{mV} /$ decade (most likely ca. $90 \mathrm{mV} /$ decade in concentrated phosphoric acid), whereas when flooded and operating under diffusion control, the electrode exhibits a behavior with a doubled Tafel slope, i.e., with a Tafel slope of $c a .180 \mathrm{mV} /$ decade.

The dependence of the oxygen reduction kinetics on the properties of platinum particles (size and structures) has been a controversial subject. In spite of the fact that earlier Zeliger, ${ }^{10}$ Bett et al., ${ }^{11}$ and later Kunz and Gruver ${ }^{7}$ and Vogel and Baris ${ }^{12}$ have shown that the oxygen reduction was independent of the platinum particle size, Blurton et al. ${ }^{13}$ and Bergoli $^{8}$ found a decrease in the specific platinum activity on oxygen reduction with diminishing particle size in 20 weight percent $(\mathrm{w} / \mathrm{o}) \mathrm{H}_{2} \mathrm{SO}_{4}$ at $70^{\circ} \mathrm{C}$ and in

* Electrochemical Society Active Member.
$99 \mathrm{w} / \mathrm{o} \mathrm{H}_{3} \mathrm{PO}_{4}$ at $177^{\circ} \mathrm{C}$, respectively. As shown by the work of Peuckert et al., ${ }^{14}$ the reason for the structure sensitivity may be associated with the adsorption of surface oxide species.

The effects of using alternative electrolyte and electrolyte additives have been explored extensively, such as fluoroalkane sulfonic acids [e.g., trifluoromethane sulfonic acid (TFMSA), ${ }^{15-17}$ and perfluoroalkane disulfonic acids ${ }^{18}$ ], perfluoro sulfonimide (e.g., PFSI ${ }^{19}$ ), and perfluorinated salts. ${ }^{20,21}$ Beneficial effects of the use of perfluorinated surfactants as additives to the phosphoric acid in PAFCs have been approved. ${ }^{21}$ A lower extent of anion adsorption of the perfluorinated additives, among others, has been suggested to be a primary factor responsible for the higher rate of oxygen reduction.

A method of analysis of the potential decay on open circuit, following interruption of a polarization current, has been developed and applied to the study of adsorption behaviors. ${ }^{22-24}$ This potential decay technique is used here to examine the adsorption behavior in oxygen reduction on gas-diffusion electrodes in phosphoric acid containing perfluorinated additives.

\section{Potential Decay Method}

For an electrode reaction the current density $i$ varies as a function of the overpotential, $\eta$

$$
i=i_{\mathrm{o}} \exp \left(\frac{\eta}{b}\right)
$$

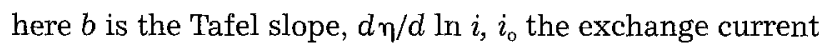
density. Under polarization conditions such that the back reaction can be neglected, the course of potential decay, $\eta(t)$, after the interruption of current, is given by the differential equation

$$
-C \frac{d \eta}{d t}=i_{0} \exp \left(\frac{\eta}{b}\right)
$$

where $C$ is the total capacitance of the electrode interface. For cases involving electroactive absorbed intermediates at significant or appreciable coverage $(\theta>0.05), C=C_{d l}+C_{p s}$. Here $C_{\mathrm{dl}}$ is the double-layer capacitance, and $C_{\mathrm{ps}}$ is the pseudocapacitance characterizing the potential dependence of the fractional coverage, $\theta$, of the electroactive intermediates

$$
C_{p s}=q_{1} \frac{d \theta}{d \eta}
$$

where $q_{1}$ is the charge required for adsorption of a monolayer.

Assuming that the capacitance $C$ is a constant independent of the potential, the integration of Eq. 2 gives the potential decay as a function of time

$$
\eta(t)=-b \cdot \ln (t+\tau)-b \cdot \ln \left(\frac{i_{o}}{C b}\right)
$$


where $\tau=b C / i$ is the integration constant and $i$ is the initial current density. The potential then changes linearly with ln $(t+\tau)$ with a slope of $b_{t}=-b$, the Tafel slope.

When $C$ is potential-dependent, in particular when $C_{\mathrm{ps}} \gg$ $C_{d l}$ the potential decay slope $b_{t}$ is characteristically either greater than or less than the Tafel slope $b$, depending on the conditions of coverage by the electroactive intermediates.

Alternatively, the total capacitance $C$ can be evaluated directly from Eq. 2 as

$$
C_{\mathrm{ps}}+C_{d l}=i_{\mathrm{o}} \exp (\eta / b) /(-d \eta / d t)
$$

or

$$
\ln \left(C_{\mathrm{ps}}+C_{\mathrm{dl} 1}\right)=-\ln (-d \eta / d t)+\ln i_{\mathrm{o}}+\eta(t) / b
$$

This can be used to obtain $C_{p s}$ as the function of $f(\eta)$.

With a digital oscilloscope and computer differentiation, the $\eta(t)$ and $d \eta / d t$ can be determined precisely from the potential relaxation following interruption of current. The time scale can be varied within 6 decades.

\section{Experimental}

Chemicals.--The preparation of $100 \mathrm{w} / 0 \mathrm{H}_{3} \mathrm{PO}_{4}$ from an aqueous 85 w/o acid (Riedel-de Häen) has been described perviously. ${ }^{2125}$ An electrolyte additive, potassium perfluorohexanesulfonate, $\mathrm{C}_{6} \mathrm{~F}_{13} \mathrm{SO}_{3} \mathrm{~K}$ (hereafter referred to as the $\mathrm{C}_{6}$ salt) was used as received in some of the experiments.

Purified hydrogen $(\geq 99.998 \%$, Hede Nielsen A/S, Denmark) and oxygen ( $\geq 99.998 \%, \mathrm{AGA} A / \mathrm{S}$ ) were used for reference and working electrodes, respectively.

The half-cell and electrodes.-A polytetrafluoroethylene (PTFE) half-cell as described previously ${ }^{25}$ was used in measurements. A platinum foil was used as the counterelectrode. A reversible hydrogen electrode (RHE) was used as the reference electrode.

Two kinds of gas-diffusion electrodes, type A and B, were used for polarization and potential decay measurements. Electrode A was purchased from Giner, Inc. Electrode B was made in this laboratory by a tape-casting process in which a slurry of Regal $660 \mathrm{R}$ carbon with $40 \%$ PTFE was used. The material contained $10 \mathrm{w} / \mathrm{o} \mathrm{Pt}$ (Pt loading $0.5 \mathrm{mg} /$ $\mathrm{cm}^{2}$ ) and was cast onto a carbon paper (Toray Europe Ltd.), dried, and sintered in nitrogen atmosphere at $360^{\circ} \mathrm{C}$ for 20 min. A set of technical data for both electrodes is listed in Table I.

During an experiment, the whole cell was placed in an oven. The temperature was controlled at $150 \pm 1^{\circ} \mathrm{C}$.

Instruments and measurements.-Tafel polarization curves were obtained by current step potentiometry. Steady-state values were recorded $100 \mathrm{~s}$ after each change of current. An electrochemical interface (SI 1286, Schlumberger Technologies Ltd.) was used for measurements.

Following each characterization of the Tafel relation, the current was interrupted and the potential relaxation transient against time was recorded digitally with an oscilloscope (DSO 1602, Gould Electronic Ltd.). Two measurements were needed for each current to maintain an adequate sampling density for a total time scale from $10^{-2}$ to $10^{4} \mathrm{~ms}$. The acquired potential data as a function of time were finally processed with a computer.

\section{Results and Discussion}

Tafel relations are first discussed to characterize the polarization behavior. In phosphoric acid with and without

\begin{tabular}{|c|c|c|}
\hline & $\begin{array}{l}\text { Electrode A } \\
\text { (Giner, Inc.) }\end{array}$ & $\begin{array}{l}\text { Electrode B } \\
\text { (This lab) }\end{array}$ \\
\hline $\begin{array}{l}\text { Pt grain size }(\AA) \\
\text { Pt/C catalyst }(\mathrm{Pt} \% \text { by weight) } \\
\left.\text { Pt loading (mg/cm }{ }^{2}\right)\end{array}$ & $\begin{array}{c}20-40 \\
10 \\
0.5\end{array}$ & $\begin{array}{c}20-60 \\
10 \\
0.5\end{array}$ \\
\hline $\begin{array}{l}\text { Carbon support } \\
\text { Surface area }\left(\mathrm{m}^{2} / \mathrm{g}\right)\end{array}$ & $\begin{array}{l}\text { Vulcan XC-72 } \\
250\end{array}$ & $\underset{112}{\text { Regal } 660 \mathrm{R}}$ \\
\hline PTFE (\%) & 40 & 40 \\
\hline
\end{tabular}

Table I. Some specifications for electrodes A and B.
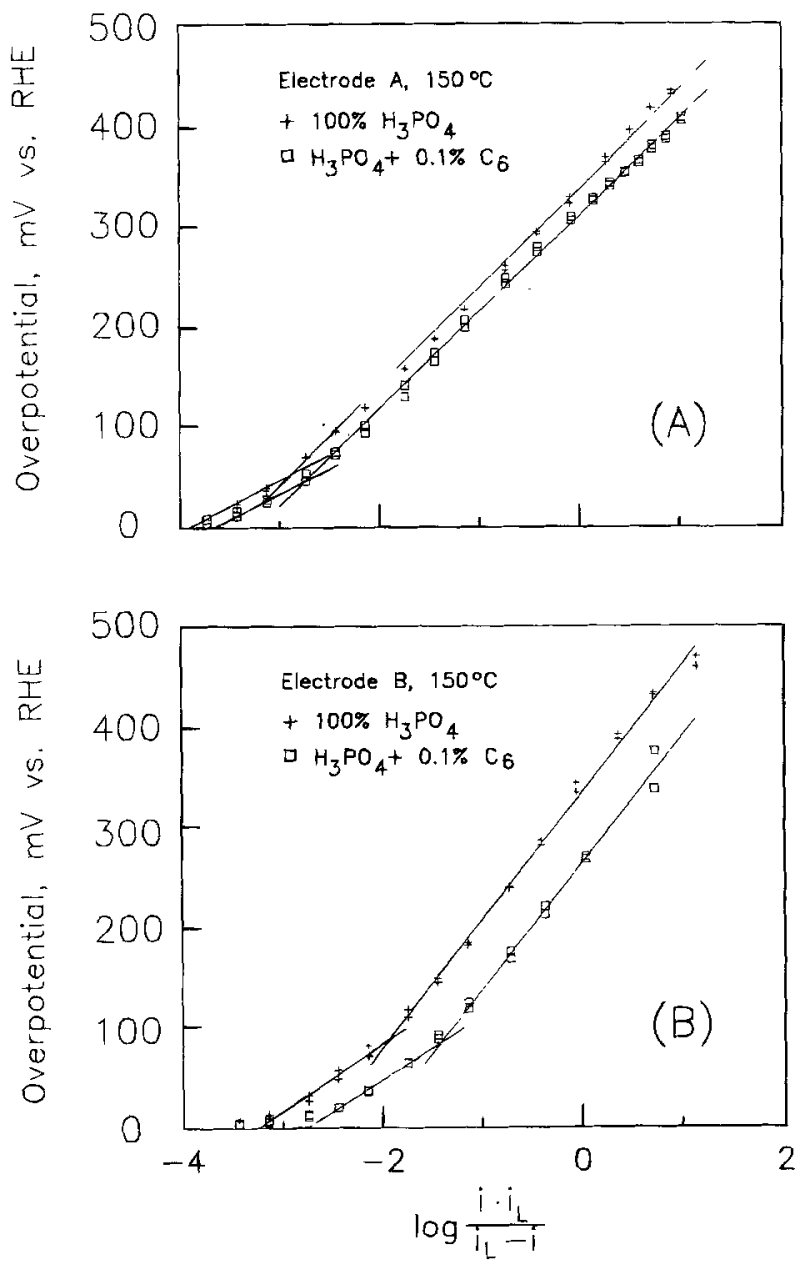

Fig. 1. Pseudo-Tafel curves in phosphoric acid both without $(+)$ and with ( $\square$ ) $0.1 \mathrm{w} / 0 C_{6}$ salt for electrode $A$ (A) and electrode (B). The solid lines were from linear regression. The two portions of data for the regression were determined visually.

the $\mathrm{C}_{6}$ salt additive at $150^{\circ} \mathrm{C}$, the plots of overpotential against log $(i)$ display curvatures at high current densities, suggesting a significant diffusion contribution of the electroactive species to the polarization, as discussed in our previous paper. ${ }^{25}$ Here $i$ is the apparent current density based on the parametric surface area of the test electrode.

The limiting current density, $i_{\mathrm{L}}$, due to diffusion of dissolved oxygen in the liquid phase was then measured. As described previously, ${ }^{25}$ at lower gaseous oxygen flow rates on the back of the electrode, the limiting current occurs due to reactant depletion or gaseous diffusion. When the oxygen flow rate was increased such that the limiting current becomes virtually constant, the current was limited due to the dissolved oxygen in the acid phase. With the limiting current density thus obtained, the pseudo-Tafel curves of overpotential against $\log \left[i i_{L} /\left(i_{L}-i\right)\right]$ can be plotted, as shown in the Fig. $1 \mathrm{~A}$ and $\mathrm{B}$. The solid lines of the figures were calculated by linear regression on two portions of data which are determined visually.

Table II. Tafel-data for the electrodes in $100 \mathrm{w} / \mathrm{o} \mathrm{H}_{3} \mathrm{PO}_{4}$ with and without $0.1 \mathrm{w} / 0 \mathrm{C}_{6}$ salt at $150^{\circ} \mathrm{C}$.

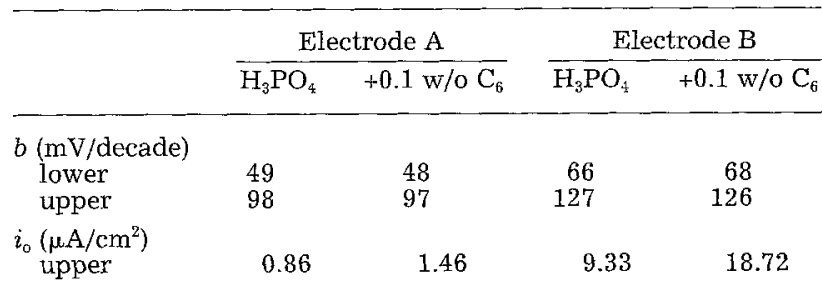


Both electrodes, and especially for cells with electrode B, exhibit two-slope Tafel relations (see Table II). At lower overpotentials the Tafel slopes were approximately half of the slopes at high overpotentials. The polarization of an electrode at a low current density was assumed to be controlled by a mixed potential between the reduction of oxygen and oxidation of carbon, platinum, and possible impurities from electrodes. ' However, as shown later, this polarization may be attributed to an essentially different adsorption mechanism.

At higher current densities, the polarization follows the Tafel relation of an electrochemical reaction. From the linear sections of the Tafel curves one can calculate Tafel slopes and exchange-current densities, as summarized in Table II.

The exchange-current density listed in Table II is based on the real reactive area of the catalyst, which was obtained from the cumulative surface area of the electrode micropores filmed with electrolyte. ${ }^{25}$ The ratios of the real surface area to the apparent surface area were thus 380 for electrode $A$ in phosphoric acid and 386 in the acid containing $0.1 \mathrm{w} / 0 \mathrm{C}_{6}$ salt, respectively. For electrode $\mathrm{B}$ in phosphoric acid and in the acid with $0.1 \mathrm{w} / 0 \mathrm{C}_{6}$ salt, the values are 510 and 515 , respectively. These real surface areas correspond to 76 (or 77) $\mathrm{m}^{2} / \mathrm{g} \mathrm{Pt}$ for electrode $\mathrm{A}$, and 102 (or 103 $\mathrm{m}^{2} / \mathrm{g}$ Pt for electrode $\mathrm{B}$ in the acid (or in the acid containing the fluorinated additive). Here the platinum loading of 0.5 $\mathrm{mg} / \mathrm{cm}^{2}$ of apparent geometric surface area was used. Compared with the theoretical calculation ${ }^{26}$ and the hydrogen adsorption/desorption technique, ${ }^{27}$ these real surface areas seem high. On this basis, however, the exchange current densities of $0.86 \cdot 10^{-6}$ and $9.33 \cdot 10^{-6} \mathrm{~A} / \mathrm{cm}^{2}$ were obtained in phosphoric acid for electrode $A$ and $B$, respectively.

With oxygen reduction on a smooth platinum electrode in $98 \mathrm{w} / \mathrm{o}_{3} \mathrm{PO}_{4}$ at $150^{\circ} \mathrm{C}$, Scharifker et al. ${ }^{5}$ found the exchange current density to be $2.6 \times 10^{-8} \mathrm{~A} / \mathrm{cm}^{2}$. However, the extrapolated value from Appleby ${ }^{3}$ to $150^{\circ} \mathrm{C}$ was ca. $6 \times$ $10^{-7} \mathrm{~A} / \mathrm{cm}^{2}$, i.e., one order higher though obtained in $85 \mathrm{w} / \mathrm{o}$ $\mathrm{H}_{3} \mathrm{PO}_{4}$. Huang et al. ${ }^{2}$ reported a value of ca. $2 \times 10^{-6} \mathrm{~A} / \mathrm{cm}^{2}$ in $84 \mathrm{w} / 0 \mathrm{H}_{3} \mathrm{PO}_{4}$. The extrapolation of the data from $O^{\prime}$ Grady et $a l^{4}{ }^{4}$ to $150^{\circ} \mathrm{C}$ yields much higher values for $i_{0}$ of about $3.5 \times 10^{-5} \mathrm{~A} / \mathrm{cm}^{2}$. The comparison of these data with those obtained on carbon-supported platinum is not straightforward, though Kunz and Gruver ${ }^{7}$ reported the same value of the exchange current for platinum black, carbon-supported platinum, and a flat platinum sheet.

From Table II we see that the Tafel slopes are 99 and $127 \mathrm{mV} /$ decade for electrode $\mathrm{A}$ and $\mathrm{B}$, respectively, in 100 w/o $\mathrm{H}_{3} \mathrm{PO}_{4}$.

Values of Tafel slopes for carbon-supported platinum electrodes are scattered in the literature, ranging from 65 to $180 \mathrm{mV} /$ decade. ${ }^{6-9}$ Tafel siopes of $c a .90 \mathrm{mV} /$ decade most frequently are reported in concentrated phosphoric acid, corresponding approximately to the ratio $(2.303 R T / F)$ in the temperature range of measurements. However, when the electrode displays a significant potential loss due to the mass transport (which is the case of an electrode with considerable thickness ${ }^{6}$ or a small PTFE content ${ }^{7,9}$ ), a double Tafel slope up to $180 \mathrm{mV} /$ decade was obtained.

Moreover, in 99 w/o $\mathrm{H}_{3} \mathrm{PO}_{4}$, Bregoli ${ }^{8}$ found that the Tafel slope increased from 90 to $110 \mathrm{mV} /$ decade as the surface area of platinum catalyst increased from 10 to $80 \mathrm{~m}^{2} / \mathrm{g}$. This dependence of the electrochemical kinetics on the electrode nature may be accountable to the difference in the Tafel slopes for both electrodes here.

In the electrolyte containing $0.1 \mathrm{w} / \mathrm{o} \mathrm{C}_{6}$ salt, the Tafel slopes remain the same for both electrodes, whereas exchange current densities are $c a$. two times larger than those in $100 \mathrm{w} / 0 \mathrm{H}_{3} \mathrm{PO}_{4}$. The introduction of perfluorinated salts into the acid, as reported, ${ }^{21}$ enhances the oxygen solubility and diffusivity of the electrolyte. As suggested previous$1 y^{16-19}$ for other perfluorinated compounds, another factor is a lower extent of ionic adsorption on the electrode surface. An increased rate of oxygen reduction in the acid containing the fluorinated additive is therefore expected.

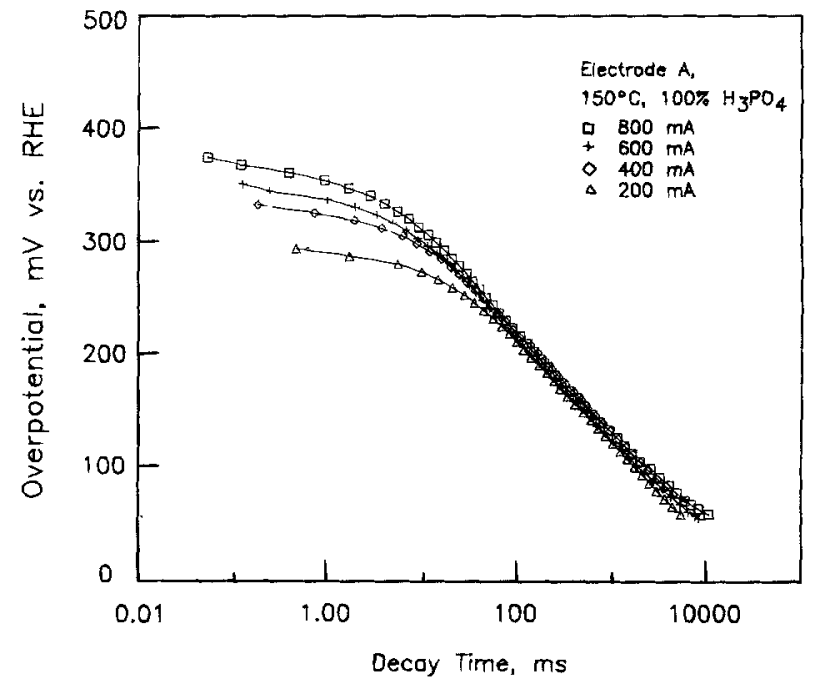

Fig. 2. Potential decay curves as a logarithmic function of time for electrode $A$ in phosphoric acid at different initial currents. The electrode working area is $0.286 \mathrm{~cm}^{2}$.

Potential decay behavior--A set of acquired potential decay data is shown in Fig. 2 as a logarithmic function of time for initial current densities (apparent) of $2.8,2.1,1.4$, and $0.7 \mathrm{~A} / \mathrm{cm}^{2}$. The integration constant, $\tau$ in Eq. 4, was evaluated such as to give a linear relation of overpotential with $\log (t+\tau)$ for short times when $t<\tau$ at the initial stage of potential decay. ${ }^{22}$ Figure 3 shows the plots of potential
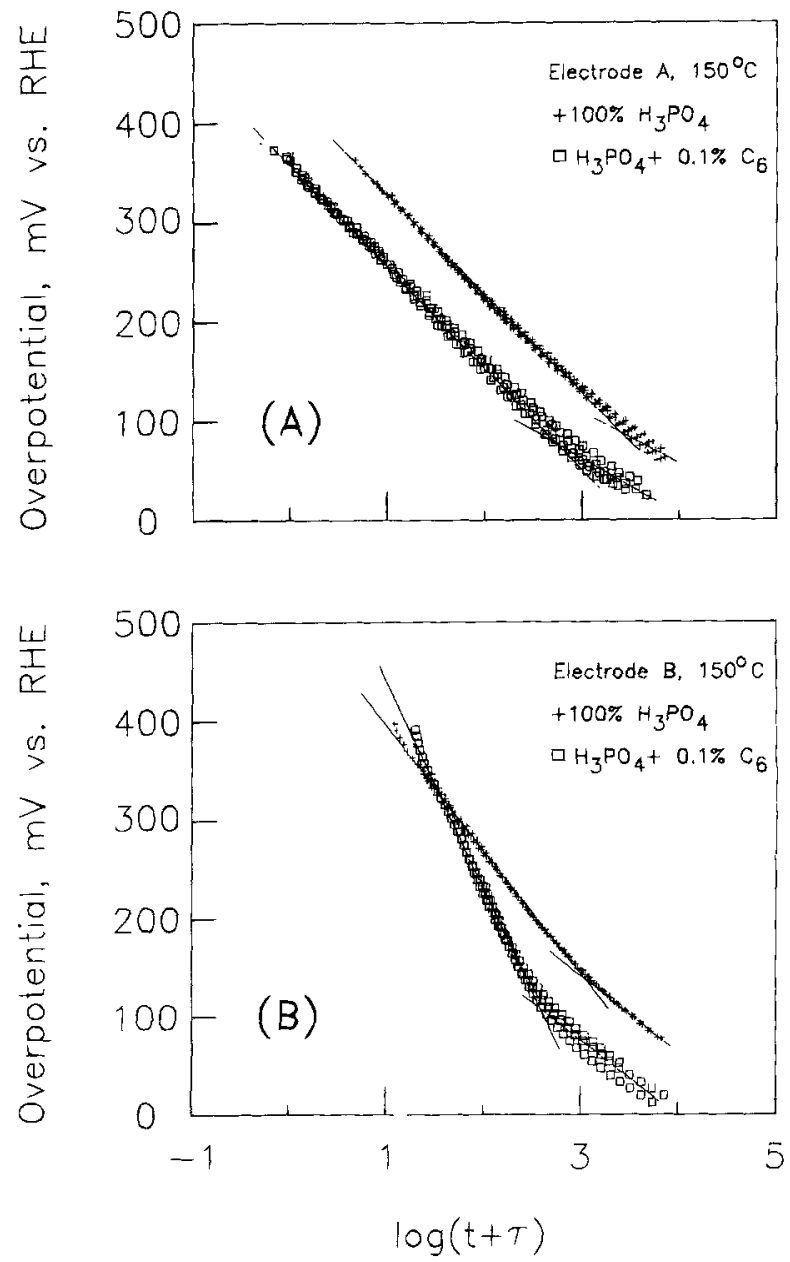

Fig. 3. Potential decay as a logarithmic function of $(t+\tau)$ in phosphoric acid both without $(+)$ and with $(\square) 0.1 \mathrm{w} / \mathrm{oC}_{6}$ salt for electrode $A(A)$ and electrode (B). For solid lines, see Fig. 1. 

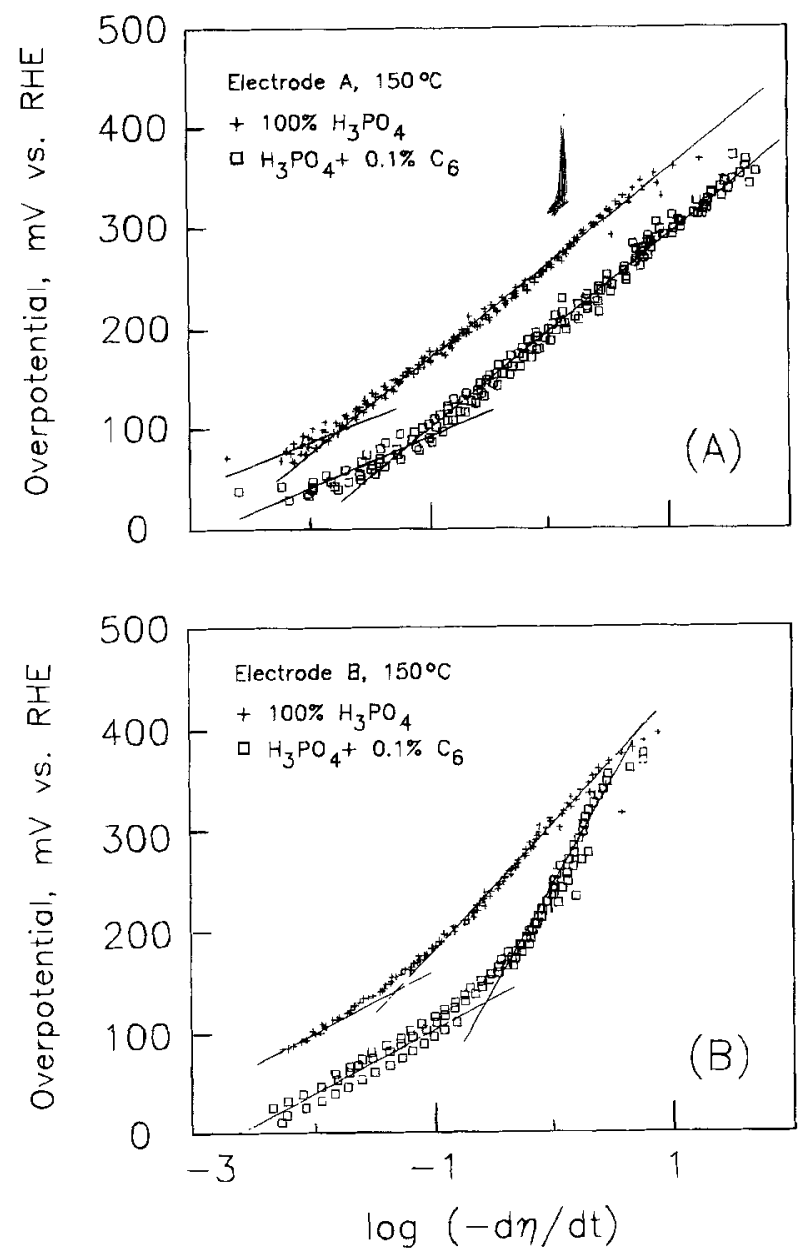

Fig. 4. Potential decay as a logarithmic function of $(-d \eta / d t)$ in phosphoric acid both without $(+)$ and with $(\square) 0.1 \mathrm{w} / 0 \mathrm{C}_{6}$ salt for electrode $A(A)$ and electrode (B). For solid lines, see Fig. 1.

against $\log (t+\tau)$ for electrodes A (Fig. 3A) and B (Fig. 3B) in phosphoric acid both with and without the fluorinated additive.

From the potential decay data acquired, $d \eta / d t$ was then obtained by differentiation. As a result the potential can be plotted as a function of $\log (-d \eta / d t)$, as shown in Fig. 4 for electrodes A (Fig. 4A) and B (Fig. 4B) in the acid both with and without the additive.

Here in Fig. 3 and 4, the solid lines are from Iinear regression for the corresponding overpotential portions which are arbitrarily assigned.

Both kinds of plots, $\eta(t)$ vs. $\log (t+\tau)$ and $\eta(t)$ vs. $\log$ $(d \eta / d t)$, display a two-slope behavior corresponding to two different Tafel relations (see Table III).

Table III. Summary of slopes obtained from polarization and potential decay measurements for Eq. 1, 4, and 6 .

\begin{tabular}{|c|c|c|c|c|}
\hline & \multicolumn{2}{|c|}{ Electrode A } & \multicolumn{2}{|c|}{ Electrode B } \\
\hline & $\overline{\mathrm{H}_{3}} \mathrm{PO}_{4}$ & $+0.1 \mathrm{w} / \mathrm{oC}_{6}$ & $\mathrm{H}_{3} \mathrm{PO}_{4}$ & $+0.1 \mathrm{w} / 0 \mathrm{C}_{6}$ \\
\hline \multicolumn{5}{|c|}{$d \eta / d \log i$ (mV/decade) } \\
\hline lower & 49 & 48 & 66 & 68 \\
\hline upper & 98 & 97 & 127 & 126 \\
\hline \multicolumn{5}{|c|}{$d \eta / d \log (t+\tau)(\mathrm{mV} /$ decade $)$} \\
\hline lower & 50 & 49 & 72 & 76 \\
\hline upper & 99 & 98 & 128 & 211 \\
\hline \multicolumn{5}{|c|}{$d \eta / d \log (-d \eta / d t)(\mathrm{m} V /$ decade $)$} \\
\hline lower & 46 & 49 & 61 & 64 \\
\hline upper & 96 & 95 & 125 & 205 \\
\hline \multicolumn{5}{|c|}{$d \log C / d \eta($ decade $/ \mathrm{mV})$} \\
\hline lower & 7.8 & 11.3 & 8.3 & 10.0 \\
\hline upper & 5.6 & 5.6 & 3.9 & 1.8 \\
\hline
\end{tabular}

For 100 w/o $\mathrm{H}_{3} \mathrm{PO}_{4}$ without the fluorinated additive, the plots of both $\eta(t) v s . \log (t+\tau)$ and $\eta(t) v s . \log (-d \eta / d t)$ have slopes identical with the corresponding Tafel slopes in both cases. This finding, in the light of Eq. 4, 5, or 6, shows that the total capacitance term $C_{\mathrm{dl}}+C_{\mathrm{ps}}$ is not significantly dependent on the electrode potential in $100 \mathrm{w} / 0 \mathrm{H}_{3} \mathrm{PO}_{4}$ in the appropriate potential range.

For the acid with the fluorinated additive, electrode $A$ exhibits slopes of $\eta(t) v s . \log (t+\tau)$ and $\eta(t) v s . \log (-d \eta / d t)$ identical to those of the Tafel relation. Electrode $B$, however, displays slopes of both $\eta(t) v s . \log (t+\tau)$ and $\eta(t) v s$. $\log (-d \eta / d t)$ much larger than those of the Tafel relation. This suggests that the total capacitance (or more precisely the pseudocapacitance $C_{\mathrm{ps}}$ ) does depend on the overpotential. The potential dependence of the fractional coverage of the absorbent is virtually expected.

Capacitance as a function of overpotential.-The total capacitance as a function of the overpotential $\eta$ can be calculated from $d \eta / d t$ by using Eq. 5 . Since $\log (-d \eta / d t)$ appears to depend linearly on $\eta$ in two potential regions, $d \log (C) / d \eta$ is apparently a constant over an appreciable range of potentials. Evidently the capacitance $C$ is an exponential function of $\eta$ over the corresponding range of overpotential, as shown in Fig. 5 and 6 for both electrodes in phosphoric acid and in the acid with the fluorinated additive.

The variation of the total capacitance as a function of the overpotential has a two-part behavior. The slopes of $\log (C)$ $v s$. overpotential for both electrodes are listed in Table III. The pseudocapacitance, $C_{\mathrm{ps}}$, defined by Eq. 3 , is responsible for the rising portion of the capacitance curves. From Fig. 5 and 6 we see that $C_{p s}$ is no more than $0.6 \mathrm{mF} / \mathrm{cm}^{2}$ for electrode A, whereas up to $2.0 \mathrm{mF} / \mathrm{cm}^{2}$, i.e., four times larger for electrode $\mathrm{B}$ in either electrolyte. The larger $C_{\mathrm{ps}}$ indicates the strong dependence of the adsorbent coverage on potential.

As the potential decays with time after current interruption, from Fig. 5 and 6 we see that the pseudocapacitance does not decrease rapidly until the overpotential is below $\sim 200 \mathrm{mV}$ ( vs. RHE for electrode $\mathrm{A}$ in $100 \mathrm{w} / \mathrm{O} \mathrm{H}_{3} \mathrm{PO}_{4}$ ). This may imply that the fractional coverage of the electrode reaches a saturation at potentials above this value. As the potential approaches the value of reversibility, the pseudocapacitance quickly increases, demonstrating the rapid change of $C_{\mathrm{ps}}$ with the potential.

In the acid with $0.1 \mathrm{w} / \mathrm{o}$ of the $\mathrm{C}_{6}$ salt, however, the potential range in which $C_{p s}$ remains virtually unchanged can be extended down to ca. $100 \mathrm{mV}$ for electrode A. For electrode $B$, this potential limit shifts from ca. $250 \mathrm{mV}$ in $100 \mathrm{w} / \mathrm{o}$ $\mathrm{H}_{3} \mathrm{PO}_{4}$ to ca. $120 \mathrm{mV}$ in the acid with $0.1 \mathrm{w} / \mathrm{o}$ of the $\mathrm{C}_{6}$ salt.

As mentioned above, the lower portion of the Tafel plot for oxygen reduction on carbon-supported platinum electrodes, which displays approximately a half Tafel slope of that at high overpotentials, was previously attributed to the oxidation of carbon, platinum, and possible impurities from electrodes. ${ }^{7}$ The rapid variation of the pseudocapacitance (which indicates the variation of the fractional coverage) in the corresponding potential range suggests an adsorption mechanism.

At higher overpotentials, the capacitance tends to reach a constant value (see the inserts in Fig. 5 and 6). The value is presumably the double-layer capacitance, $C_{\mathrm{dl}}$, for the electrode under the prevailing experimental conditions. Obtained double-layer capacitances are 0.007 and $0.012 \mathrm{mF} / \mathrm{cm}^{2}$ for electrode $A$ and 0.027 and $0.043 \mathrm{mF} / \mathrm{cm}^{2}$ for electrode $B$, in the acid without and with the fluorinated additive, respectively.

The double-layer capacitance can be correlated with the parameters of gas-diffusion electrodes such as carbon supporting, PTFE content, sintering temperature, and the electrolyte wettability as well. These different values of the double-layer capacitance for two kinds of electrodes can be at least partially accounted for by the use of different carbon powders. Some results of the double-layer capacitance, as a function of carbon materials, are listed in Table IV. For most literature data, the double-layer capac- 
Fig. 5. Total capacitance as a function of overpotential for electrode $A$ in phosphoric acid bolh without (+) and with (ㅁ) 0.1 w/o $C_{6}$ salt. Inserted figure (a) is on an expanded scale. For solid lines, see Fig. 1.
Fig. 6. Total capacitance as a function of overpolential for electrode $B$ in phosphoric acid both without $(+)$ and with ( $\square) 0.1 \mathrm{w} / \mathrm{o}$ $C_{6}$ salt. Inserted figure $(a)$ is on an expanded scale. For solid lines, see Fig. 1.
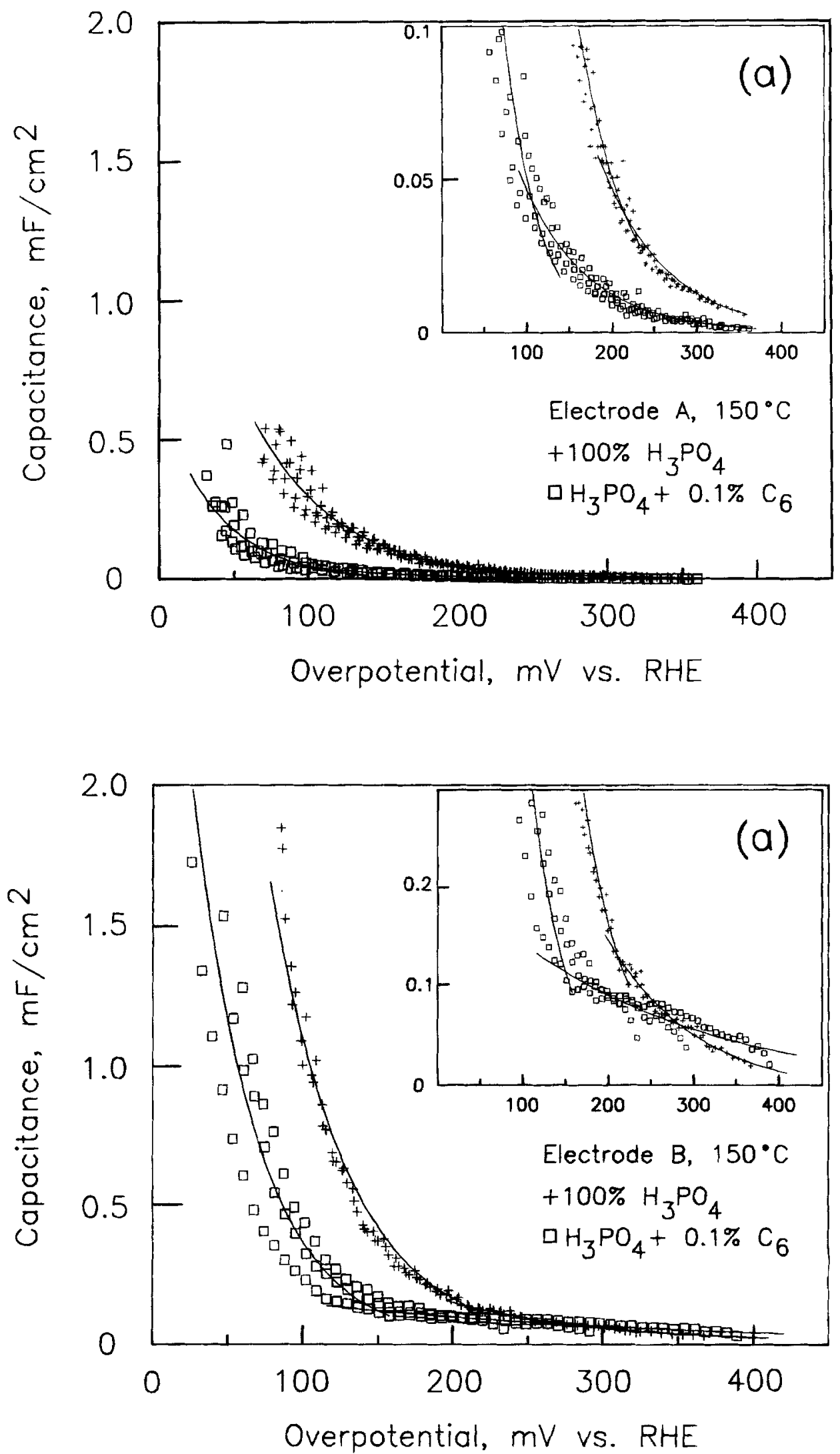

ities on the basis of the perimetric area were measured from cyclic voltammograms, and then divided by the Brunauer, Emmett, and Teller method (BET) surface area to obtain the real double-layer capacities on the basis of the reactive area. The comparison of these data is not straightforward because of the complexity of the experimental situation. As can be noted from Table IV, the double-layer capacitance of electrode B (with Regal 660R, $112 \mathrm{~m}^{2} / \mathrm{g}$ ) is probably larger than the electrode A (with Vulcan XC-72, $250 \mathrm{~m}^{2} / \mathrm{g}$ ).
This may be due to the difference in the degree of dispersion of platinum particles on the surface of the carbon supports. Since the platinum loading and platinum particle size range are virtually the same for both electrodes, one may expect a dense dispersion of platinum particles on the low-surface-area carbon support (e.g., Regal 660R for electrode B). The dense dispersion of platinum particles may enhance the wettability of the electrode. This seems confirmed by the acid adsorption measurements for 
Table IV. Double-layer capacitance with different carbon blacks compared with the results from the present study.

\begin{tabular}{|c|c|c|c|c|c|}
\hline Carbon black & $\begin{array}{l}\text { Specific } \\
\text { area } \\
\left(\mathrm{m}^{2} / \mathrm{g}\right)\end{array}$ & Electrolyte & Technique & $\begin{array}{c}C_{\mathrm{dl}} \\
\left(\mathrm{mF} / \mathrm{cm}^{2}\right)\end{array}$ & Ref. \\
\hline Ketjenblack (Armak) & 1000 & $1 M \mathrm{NaOH}$ & Voltammetry & 0.0037 & 28 \\
\hline Carbonpack B(Supelco) & 100 & $0.01 \mathrm{M} \mathrm{NaCl}$ & Voltammetry & 0.0043 & 29 \\
\hline Carbonpack B(Supelco) & 100 & $0.1 \mathrm{M} \mathrm{NaCl}$ & Voltammetry & -0.0045 & 30 \\
\hline Vulcan XC-72 (Cabot) & 250 & $31 \mathrm{w} / \mathrm{o} \mathrm{KOH}$ & Voltammetry & 0.010 & 31 \\
\hline Vulcan XC-72 (Cabot) & 250 & $1 \mathrm{M} \mathrm{H}_{2} \mathrm{SO}_{4}$ & Voltammetry & 0.008 & 32 \\
\hline Vulcan XC-72 (Cabot) & 250 & $96 \mathrm{w}^{\circ} \mathrm{o} \mathrm{H}_{3} \mathrm{PO}_{4}$ & ac impedance & $0.01-0.02$ & 33 \\
\hline Acetylene black (Gulf) & 65 & $1 M \mathrm{NaOH}$ & Voltammetry & 0.019 & 28 \\
\hline Vulcan XC-72 (Cabot) & 250 & $100 \mathrm{w} / \mathrm{o} \mathrm{H}_{3} \mathrm{PO}_{4}$ & Potential decay & 0.007 & a \\
\hline Vulcan XC-72 (Cabot) & 250 & $\mathrm{H}_{3} \mathrm{PO}_{4}+0.1 \% \mathrm{C}_{6}$ salt & Potential decay & 0.012 & a \\
\hline Regal 660R (Cabot) & 112 & $100 \mathrm{w} / \mathrm{o} \mathrm{H}_{3} \mathrm{PO}_{4}$ & Potential decay & 0.019 & a \\
\hline Regal 660R (Cabot) & 112 & $\mathrm{H}_{3} \mathrm{PO}_{4}+0.1 \% \mathrm{C}_{6}$ salt & Potential decay & 0.036 & a \\
\hline
\end{tabular}

a Present study.

both electrodes in our previous paper. ${ }^{25}$ Data in Table IV appear to approve this assumption. For instance, three types of carbon blacks with alkaline electrolyte, i.e., Ketjenblack $\left(1000 \mathrm{~m}^{2} / \mathrm{g}\right)$, Vulcan XC-72 $\left(250 \mathrm{~m}^{2} / \mathrm{g}\right)$, and acetylene $\left(65 \mathrm{~m}^{2} / \mathrm{g}\right)$, showed double-layer capacitances of 0.0037 , 0.010 , and $0.019 \mathrm{mF} / \mathrm{cm}^{2}$, respectively.

As Mokrousov et al. ${ }^{34}$ found in their charging curve measurement, the electrode wettability with different electrolytes has a considerable influence on the measured values of the double-layer capacitance, i.e., the increase in the wetted surface area of the activated carbon may lead to a larger double-layer capacitance. The presence of the fluorinated compound in the phosphoric acid has a dramatic effect on the wettability ${ }^{20}$ and the electrocapillary property (i.e., surface tension ${ }^{35}$ ) of the electrolyte. An increased double-layer capacitance was hence expected when a dense dispersion of $\mathrm{Pt}$ particles was present or especially when the $\mathrm{C}_{6}$ salt was introduced into the electrolyte.

The transition potentials of the two-part capacitance curves of both electrodes, upon the addition of the perfluorinated compounds, decrease by ca. $100 \mathrm{mV}$, i.e., from ca. $220 \mathrm{mV}$ to $c a .120 \mathrm{mV}$ for electrode A and from $c a .240 \mathrm{mV}$ to ca. $140 \mathrm{mV}$ for electrode B. This may indicate that the saturating adsorption of electrolyte ions is reached at lower overpotentials when the additive is present. When the additive is added, there may be more active sites on the electrode surface available for the electrochemical reduction of oxygen because of the weakened adsorption of the electrolyte ions.

Since the zero-charge potential for platinum in acid solution is 0.5 to $0.7 \mathrm{~V}$ vs. $\mathrm{RHE},{ }^{18}$ one may expect that, in the potential range for oxygen reduction $(0.7$ to $1.0 \mathrm{~V})$, the platinum surface is positively charged, and all anions in the electrolyte are drawn to the inner Helmholtz layer, while the cations are repelled from the inner layer. This potential range for anion adsorption corresponds to overpotentials up to ca. $0.3 \mathrm{~V}$ vs. RHE here, see, e.g., Fig. 5 and 6 . The competition among anions in the electrolyte depends on the relative strength of the ion-solvent interaction and the ionmetal interaction. As shown by Saffarian et al., ${ }^{18}$ the ionmetal interaction for inorganic anions such as sulfate, phosphate, and chloride is stronger than that for the anions of perfluoroalkane sulfonate family.

Apart from the increased solubility and diffusion coefficient of oxygen, ${ }^{21,25,35}$ when the perfluorinated salts are present in phosphoric acid, the lower extent of anion adsorption on the catalyst surface is presumably another primary factor responsible for the enhanced kinetics of oxygen reduction, as previously proposed for other perfluorinated additives by Zelenay et $a l .,{ }^{17}$ Saffarian et al., ${ }^{18}$ and Razaq et $a l .{ }^{19}$

\section{Conclusion}

The oxygen reduction on carbon-supported platinum electrodes in phosphoric acid has been studied by steadystate polarization and potential decay measurements. Tafel curves display a two-slope linear relation. The slope variations and the potential-dependence of the capacitances show that the lower portion of the Tafel plot can be appreciably attributed to a different adsorption mechanism.

The potential decays $v s$. $\log (t+\tau)$ and $v s . \log (-d \eta / d t)$ show a behavior in accordance with the Tafel plots. The variations of slopes depended on the kind of electrode (originating from the manufacturing process) and the electrolyte. The double-layer capacitance and the pseudocapacitance due to the ionic adsorption were obtained from the potential decay measurements as a function of the overpotential.

Potassium perfluorohexanesulfonate $\left(\mathrm{C}_{6} \mathrm{~F}_{13} \mathrm{SO}_{3} \mathrm{~K}\right)$ when added into the phosphoric acid electrolyte may lead to an enhanced oxygen reduction kinetics. The reduced adsorption of the perfluorinated anions, as well as the increased oxygen solubility and diffusion coefficient, is a primary factor responsible for the enhanced kinetics.

Manuscript submitted Nov. 21, 1994; revised manuscript received June 19, 1995

\section{REFERENCES}

1. D. B. Sepa, M. V. Vojnovic, and A. Damjanovic, Electrochim. Acta, 26, 781 (1981).

2. J. C. Huang, R. K. Sen, and E. Yeager, This Journal, 126, $786(1979)$.

3. A. J. Appleby, ibid., 117, 328 (1970).

4. W. E. O'Grady, E. J. Taylor, and S. Srinivasan, J. Electroanal. Chem. 132, 137 (1982)

5. B. R. Scharifker, P. Zelenay, and J. O'M. Bockris, This Journal, 134, 2714 (1987).

6. P. Stonehart and P. N. Ross, Jr., Electrochim. Acta, 21, 441 (1976)

7. H. R. Kunz and G. A. Gruver, This Journal, 122, 1279 (1975).

8. L. J. Bregoli, Electrochim. Acta, 23, 489 (1978).

9. M. Watanabe, K. Makita, H. Usami, and S. Motoo, J. Electroanal. Chem., 197, 195 (1986).

10. H. I. Zeliger, This Journal, 114, 144 (1967).

11. J. Bett, J. Lundquist, E. Washington, and P. Stonehart, Electrochim. Acta, 18, 343 (1973).

12. W. M. Vogel and J. M. Baris, ibid., 22, 1259 (1977).

13. K. F. Blurton, P. Greenberg, H. G. Oswin, and D. R. Rutt, This Journal, 119, 559 (1972).

14. M. Peuckert, T. Yoneda, R. A. Dalla Betta, and M. Boudart, ibid., 133, 944 (1986)

15. A. J. Appleby and B. Baker, ibid., 125, 504 (1978).

16. M. A. Enayetullah, E. J. M. O'Sullivan, and E. B. Yeager, J. Appl. Electrochem., 18, 763 (1988).

17. P. Zelenay, B. R. Scharifker, and J. O'M. Bockris, This Journal, 133, 2262 (1986).

18. H. Saffarian, P. Ross, F. Behr, and G. Gard, ibid., 139, $2391(1992)$

19. M. Razaq, A. Razaq, E. Yeager, D. D. DesMarteau, and S. Singh, ibid., 136, 385 (1989).

20. X. Gang, Ph.D. Thesis, Technical University of Denmark, Lyngby, Denmark (1991).

21. X. Gang, H. A. Hjuler, C. Olsen, R. W. Berg, and N. J. Bjerrum, This Joumal, 140, 896 (1993).

22. B. E. Conway, L. Bai, and D. F. Tessier, J. Electroanal. Chem., 161, 39 (1984)

23. B. E. Conway and L. Bai, J. Chem. Soc., Faraday Trans. 1, 81, 1841 (1985). 
24. B. E. Conway and L. Bai, Electrochim. Acta, 31, 1013 (1986).

25. L. Qingfeng, X. Gang, H. A. Hjuler, R. W. Berg, and N. J. Bjerrum, This Journal, 141, 3114 (1994).

26. P. Stonehart, J. Appl. Electrochem., 22, 995 (1992).

27. J. Aragane, H. Urushibata, and T. Murahashi, This Journal, 141, 1804 (1994).

28. J. A. Molla, Ph.D. Thesis, Case Western Reserve University, Cleveland, OH (1983)

29. Y. Oren and A. Soffer, This Journal, 125, 869 (1978).

30. Y. Oren, H. Tobias, and A. Soffer, J. Electroanal. Chem.,
162, 87 (1985).

31. E. G. Gagnon, This Journal, 122, 521 (1975).

32. K. Kinoshita and J. A. S. Bett, Carbon, 11, 403 (1973).

33. J. McHardy, J. K. Baris, and P. Stonehart, J. Appl. Electrochem., 6, 371 (1976).

34. L. N. Mokrousov, N. A. Urisson, and G. V. Shteinberg, Electrikhimiya, 9, 683 (1973).

35. L. Qingfeng, X. Gang, H. A. Hjuler, R. W. Berg, and N. J. Bjerrum, Abstract No. 621, p. 973, The Electrochemical Society Extended Abstracts, Vol. 94-2, Miami Beach, FL, Oct. 9-14, 1994.

\title{
Numerical Simulation of the Cyclic Voltammogram of Polyacetylene
}

\author{
E. Deiss and O. Haas* \\ Paul Scherrer Institute, $\mathrm{CH}-5232$ Villigen, Switzerland
}

J. B. Schlenoff

Department of Chemistry, The Florida State University, Tallahassee, Florida 32306-3006, USA

ABSTRACT

The measured cyclic voltammogram of a polyacetylene-coated electrode bathed in an electrolyte solution was simulated numerically for various scan rates. The model used accounts for a modified Butler-Volmer-type heterogeneous kinetics at the electrode surface including a lateral interaction term which effects the observed hysteresis behavior. Within the polymer an electron flux obeying Ohm's law as well as electrolyte diffusion and migration is considered and Poisson's equation holds for electroneutrality. Donnan partition kinetics describes the flux and potential at the interface between the polymer and diffusion layer. Electrolyte diffusion is considered in the diffusion layer.

\section{Introduction}

In 1977 it was shown by Shirakawa et al. that oxidation (also called doping) of polyacetylene (PA) enhances its electrical conductivity by many orders of magnitude and provides the polymer with metallic properties. ${ }^{1,2}$ This conductivity behavior is common to the conducting polymers, which consist of electrochemically active $\pi$-conjugated chains, and to which PA belongs (for a review on conducting polymers see Ref. 3 and reviews cited therein). Much effort has been invested in conducting polymers in order to develop a rechargeable polymer battery. Analyzing the cyclic voltammograms (CV) of conducting polymers is a commonly used method for investigating the electrochemical behavior and a considerable amount of work has been done in understanding these data.

The CV of PA given in Fig. 2 is typical for conducting polymers. It shows an anodic peak which is sharper than the cathodic one. With decreasing scan rates the peak separation between anodic and cathodic peaks approaches a quasi-reversible value $\Delta E_{\mathrm{p}}^{\mathrm{qr}}$ of $344 \mathrm{mV}$. In contrast to experimental findings, theoretical considerations predict that such polymer-modified electrodes should have mirrorsymmetric anodic and cathodic peaks with $\Delta E_{\mathrm{p}}^{\mathrm{qr}}=0 .{ }^{4,5}$ This means that the peak separation should approach zero with decreasing scan rates. The experimentally observed nonzero $\Delta E_{\mathrm{p}}^{\mathrm{qr}}$ was interpreted by some authors to result from sluggish kinetic parameters, ${ }^{5-10}$ but these interpretations necessarily lead to a $\Delta E_{\mathrm{p}}^{\mathrm{gr}}$ of zero at very low scan rates, which is in contrast to experimental observations. Heinze et al. ${ }^{11}$ explained the peak separation at low scan rates as a consequence of a conformational change upon oxidation where the conformations have different standard potentials which cause a nonzero $\Delta E_{\mathrm{p}}^{\mathrm{qr}}$. Although their simulations show peak separations in the quasi-reversible case, it was shown by Feldberg and Rubinstein ${ }^{12}$ that Heinze's

* Electrochemical Society Active Member. model must lead to a $\Delta E_{0}^{\mathrm{qr}}$ of zero in contrast to Heinze's calculations. Our own numerical simulations support the conclusions of Feldberg and Rubinstein because in square schemes as proposed by Heinze the steady-state concentration profiles at a given potential are unique and independent of whether the scan is anodic or cathodic. As a consequence, $\Delta E_{\mathrm{p}}^{\mathrm{qr}}$ of such square scheme systems is zero. Laviron $^{4,13}$ and more recently Feldberg and Rubinstein ${ }^{12}$ explained the nonzero $\Delta E_{\mathrm{p}}^{\mathrm{qr}}$ in the CV of polymer-coated electrodes as a consequence of a hysteresis caused by strong lateral interactions between redox centers as manifested by S-shaped Frumkin-type adsorptions isotherms. ${ }^{14}$ Hysteresis effects of CVs of adsorbed layers have also been interpreted in terms of S-shaped isotherms by Gileadi, ${ }^{15}$ Laviron, ${ }^{1 \hat{}}$ and Sadkowski ${ }^{17}$ (a review on CV of adsorbed layers is given by Laviron ${ }^{18}$ ).

Another conspicuous feature in CVs of conducting polymers is what Feldberg ${ }^{5}$ calls capacitive current. He explains the broad anodic tail on the high potential side of the $\mathrm{CV}$ as a capacitive charging which is proportional to the amount of oxidized polymer centers. In contrast to this interpretation Heinze et al. ${ }^{19}$ concluded from their experiments that this anodic tail is mainly caused by faradaic current and attributed this shape behavior to a variation of redox state energies with a reasonable number of low lying degenerate states followed by redox states with increasingly higher energies. ${ }^{11}$ Schlenoff et al. ${ }^{20}$ estimated the amount of Feldberg's capacitive current and concluded that this can be neglected.

Due to the complexities mentioned above, the simulation of experimental CVs of conducting-polymer-coated electrodes is not an easy job and only a few works address this matter. Feldberg ${ }^{5}$ published a simulated $\mathrm{CV}$ of polypyrrole using a small heterogeneous rate constant to get the observed peak separation $\Delta E_{\mathrm{g}}^{\mathrm{qr}}$. Heinze's simulation of polypyrrole $^{11}$ with its problematic peak separation has been mentioned above. Yeu et $a l .^{21}$ published another well- 